\title{
Gall Bladder Wall Thickness as a Predictor for Laparoscopic Cholecystectomy Difficulties in Gadarif, Eastern Sudan
}

\author{
Sami E. E. Salah and Hawa Yahia
}

\section{ABSTRACT}

Background: Laparoscopic cholecystectomy is a revolutionary change in the treatment of patients with gallbladder stones. Multiple studies have identified factors that are predictive of surgical difficulties including preoperative ultra-sonographic findings.

Objective: To determine the effectiveness of sonographic measurement of gall bladder wall thickness as a predictive factor for laparoscopic cholecystectomy difficulties in Gadarif Teaching Hospital, Sudan.

Patients and methods: This are a prospective, observational, analytical cross-sectional hospital-based study in which all patients who underwent laparoscopic cholecystectomy for gall stones disease and had a preoperative sonographic measurement for GBWT in GTH in the year 2019 were included.

Results: 110 cases were studied. The male to female ratio was $0.2: 1$, the mean age was $35 \pm 3.8$ years. Past history of the acute attack reported in 54 $(48.2 \%)$ of the patients, history of ERCP was reported in $2(1.8 \%)$ and the majority of patients $71(64.5 \%)$ has no associated medical condition. Abdominal examination was normal in $69(62.7 \%)$ of the patients, 35 $(31.8 \%)$ patients showed positive Murphy's sign or other signs. Gall bladder thickening, as a predictor of difficulty, was normal of $\leq \mathbf{3 m}$ in $69(62.7 \%)$, mild $(4-5 \mathrm{~mm})$ in $34(30.9 \%)$, moderate $(6-7 \mathrm{~mm})$ in $5(4.5 \%)$, and severe $>7$ in $2(1.8 \%)$ of the patients. A significant association was found between GBWT and: duration of symptoms, the number of attacks, operative time and hospital stay, postoperative complication, and conversion to open cholecystectomy. Operative time was found to be associated with the experience of the operator $(P$-value $<0.05)$.

Conclusion: Pre-operative sonographic increasing gall bladder wall thickness is associated with difficult laparoscopic cholecystectomy in terms of postoperative complications, prolonged operative time, and conversion to open cholecystectomy even in expert hands.

Keywords: Gadarif, Laparoscopy, Sudan, Ultrasound
Published Online: July 24, 2021

ISSN: $2736-5476$

DOI: $10.24018 /$ ejclinicmed.2021.2.3.77

Sami E. E. Salah *

University of Gadarif, Gadarif, Sudan.

(e-mail: samieldirdiri@gmail.com)

Hawa Yahia

Gadarif Teaching Hospital, Sudan.

(e-mail: hawayahia8@gmail.com)

*Corresponding Author

\section{INTRODUCTION}

Laparoscopic cholecystectomy is a revolutionary change in the treatment of patients with gallbladder stones [1]. The first laparoscopic cholecystectomy worldwide was performed in 1985 [2] and it was introduced in Sudan by 1995 [3]. The procedure was introduced in Gadarif (Eastern Sudan) a decade later, in 2005, and since then, many surgeons and residence are practicing it as the most common laparoscopic procedure.

Transabdominal ultrasonography (US) is the initial imaging modality of choice as it is accurate, readily available, inexpensive, and quick to perform. The size of the gallbladder can be seen, the presence of stones or polyps determined, and the thickness of the wall measured. The significance of
GBWT on sonographic measurement for diagnostic accuracy and surgical difficulties was documented before the era of laparoscopy [4]. Multiple studies have identified factors that are predictive of surgical difficulties including preoperative US findings. Among these factors is gallbladder wall thickness, which has been shown to be associated with increased risk of conversion to open procedure [5].

\section{PATIENTS AND METHODS}

This is a prospective, observational, and analytic, cross sectional hospital-based study.

\section{A. Study Area}

The study was conduct in Gadarif Teaching Hospital in eastern Sudan. Gadarif State is at an altitude of $496 \mathrm{~m}$ above 
sea level, covering an area of 75,000 $\mathrm{km}^{2}$, and lies between latitudes 14 and 16 north and longitudes 33 and 36 East with a population a little over 1.7 million residents. It is $410 \mathrm{~km}$ from the capital of Sudan on the Ethiopian border. GTH is a 170-bed public governmental tertiary care facility that serves as a referral center in Gadarif State. Laparoscopic surgery was introduced in 2006. The Surgical department, including orthopedics and plastic, is staffed with 8 consultants and specialists and 15 registrars (residents) enrolled in the national training program.

\section{B. Study Requisite}

Pre-operative sonographic measurement of gall bladder wall thickness was done to all study population as predictor of inflammation categorizing them into 4 groups according to GBWT [5]: Normal: 1-3 mm, Mild: 4-5 mm, Moderate: 6$7 \mathrm{~mm}$, Severe: more than $7 \mathrm{~mm}$.

\section{Inclusion and Exclusion Criteria}

All symptomatic gall stones patients underwent laparoscopic cholecystectomy in GTH in the year 2019 were included, excluding those whom their GBWT was not determined in the pre-operative US.

\section{Sample Size}

Was calculated using the formula:

$$
\mathrm{n}=\mathrm{Z} \times \mathrm{Z} \times(1-\mathrm{P}) \times \mathrm{P} \times \mathrm{D} 2 .
$$

where

$\mathrm{Z}=$ Value of $95 \%$ confidence interval, which is the normal standard deviation $=1.96$,

$\mathrm{P}=$ prevalence of LC difficulties from the literature $=10.0 \%$.

$\mathrm{D}=$ difference in precision or estimate $=0.05$ or $5 \%$.

Using the formula, sample size of 110 was obtained by simple random technique.

\section{E. Questionnaire}

Data was collected using a detailed and structured questionnaire which was filled by the operating doctor (selfadministered).

\section{F. Data Entry and Analysis}

Data was analyzed using Statistical Package for the Social Science SPSS version 22.0 software. Dependent variable, percentage, mean, standard deviation and range are calculated. Binary logistic regression and one-way analysis of variance was use for analytic assessment. P values $<0.05$ was consider as statistically significant

\section{G. Ethical Consideration}

Ethics approval was obtained from the Ethics Committee of the Faculty of Medicine of Gadarif University (Reference number: GU/FM/REC Q3.1.19.01), and Sudan Medical Specialization Board Sudan. Written informed consent was obtained from each participant.

\section{RESULTS}

The common tribal origin among the patients was eastern tribes $49(44.5 \%)$, the majority $84(76.4 \%)$ were unemployed housewives, highest percentage $43(39.1 \%)$ not educated.
Males were 17 (15.5\%) and females were 93 (84.5\%). Male to female ratio was $0.2: 1$. The common age group was $31-$ 40 years in $31(28.2 \%)$. The mean age was $35 \pm 3.8$ years (Table I).

The main presenting symptoms were right hypochondrial pain $98(89.1 \%)$, dyspepsia $68(61.8 \%)$, nausea and vomiting $44(40 \%)$, jaundice and itching $3(2.7 \%)$ 'and fever and rigors in $3(2.7 \%)$ patients. (Fig. 1).

\begin{tabular}{|c|c|c|c|}
\hline Variable & Result & $\mathbf{N}$ & $\%$ \\
\hline \multirow[t]{4}{*}{ Tribe } & Northern & 22 & 20.0 \\
\hline & Central & 14 & 12.7 \\
\hline & Western & 25 & 22.7 \\
\hline & Eastern & 49 & 44.5 \\
\hline Total & & 110 & 100.0 \\
\hline \multirow[t]{3}{*}{ Occupation } & Not working & 84 & 76.4 \\
\hline & Employee & 13 & 11.8 \\
\hline & Worker & 13 & 11.8 \\
\hline Total & & 110 & 100.0 \\
\hline \multirow[t]{4}{*}{ Education } & Not educated & 43 & 39.1 \\
\hline & Primary & 17 & 15.5 \\
\hline & Secondary & 29 & 26.4 \\
\hline & University & 21 & 19.1 \\
\hline Total & & 110 & 100.0 \\
\hline \multirow[t]{2}{*}{ Gender } & Male & 17 & 15.5 \\
\hline & Female & 93 & 84.5 \\
\hline Total & & 110 & 100.0 \\
\hline \multirow[t]{9}{*}{ Age group } & $<10$ years & 1 & 0.9 \\
\hline & $11-20$ years & 3 & 2.7 \\
\hline & $21-30$ years & 22 & 20.0 \\
\hline & $31-40$ years & 31 & 28.2 \\
\hline & $41-50$ years & 18 & 16.4 \\
\hline & $51-60$ years & 15 & 13.6 \\
\hline & $61-70$ years & 12 & 10.9 \\
\hline & $71-80$ years & 7 & 6.4 \\
\hline & $81-90$ years & 1 & 0.9 \\
\hline Total & & 110 & 100.0 \\
\hline
\end{tabular}

The maximum duration of symptoms was 1-3 years in 41 (37.3\%) of the patients (Fig. 2).

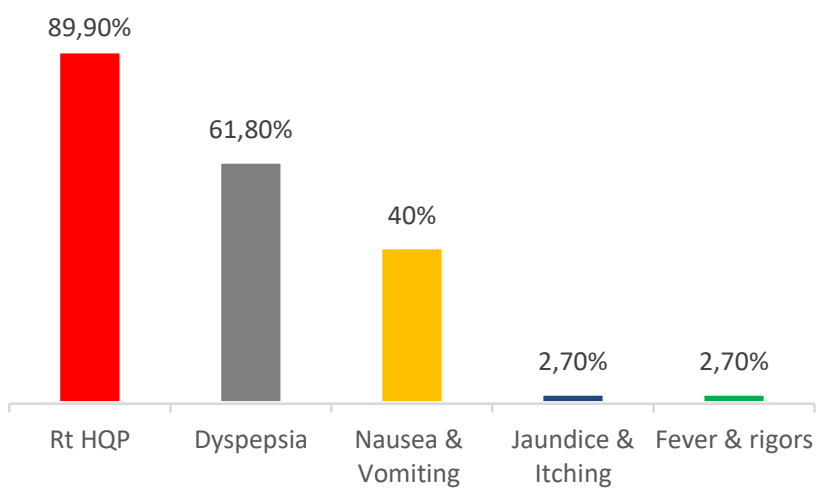

Fig. 1. Presenting Symptom.

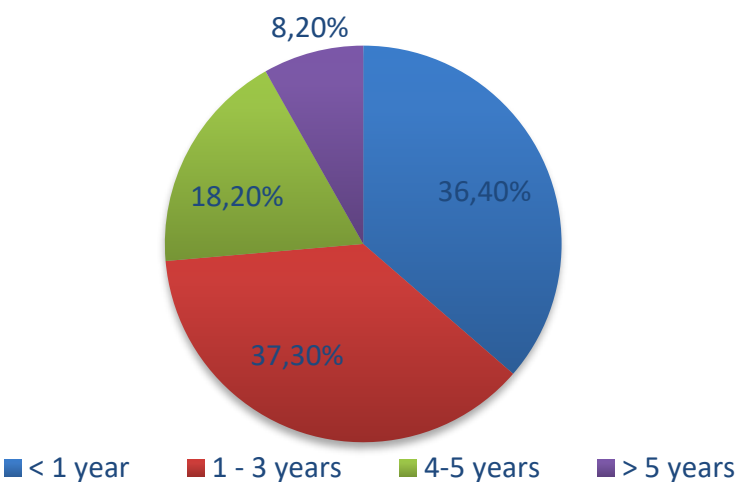

Fig. 2. Duration of Symptoms. 
In majority of the patients $71(64.5 \%)$ there was no associated condition, the reported conditions were hypertension $16(14.5 \%)$, abdominal scar $6(5.5 \%)$, diabetes $5(4.5 \%)$, hypertension with diabetes $4(3.6 \%)$, pregnancy 2 (1.5\%), ovarian cyst $2(1.8 \%)$, asthma 2 (1.8\%), hypothyroidism $1(0.9 \%)$ and Chronic lymphoid Leukemia in $1(0.9 \%)$ patient.

Personal history of acute attack reported in 54 (48.2\%) of the patients. The number of attacks was 2-5 attacks 24 (44.4\%), single $22(40.7 \%)$ and more than 5 in $8(14.8 \%)$ of the patients. Personal history of ERCP was reported in 2 $(1.8 \%)$ of the patients. (Table II).

\begin{tabular}{|c|c|c|c|}
\hline History & & $\mathrm{N}$ & $\%$ \\
\hline \multirow[t]{2}{*}{ Personal history of acute attack } & Yes & 54 & 48.2 \\
\hline & No & 56 & 51.8 \\
\hline \multirow{4}{*}{ Number of attacks } & & 110 & 100.0 \\
\hline & Single & 22 & 40.7 \\
\hline & $2-5$ attacks & 24 & 44.4 \\
\hline & $>5$ attacks & 8 & 14.8 \\
\hline Total & & 54 & 100.0 \\
\hline \multirow[t]{2}{*}{ Personal history of ERCP } & Yes & 2 & 1.8 \\
\hline & No & 108 & 98.2 \\
\hline Total & & 110 & 100.0 \\
\hline
\end{tabular}

In abdominal examination $69(62.7 \%)$ of the patients were normal, 35 (31.8\%) showed Murphy's sign, and other signs are shown in Table (V). Total WBC was 4000-11000 in 71 $(64.5 \%)$ of the patients, 4000 in $35(31.8 \%)$ and above 11000 in $4(3.6 \%)$. Liver function tests were normal in $75(68.2 \%)$ of the patients, not done $32(29.1 \%)$ and abnormal $3(2.7 \%)$. Coagulation profile was normal in $70(63.6 \%)$ of the patients, not done $38(34.5 \%)$ and abnormal $2(1.8 \%)$.

Gall bladder wall thickness was normal (1-3) in $69(62.7 \%)$ of the patients, mild thickening (4-5) in 34 (30.9\%), moderate (6-7) in $5(4.5 \%)$ and severe $>7$ in 2 (1.8\%) (Fig. 4). The number of stone was multiple in $89(80.9 \%)$ and single in $21(19.1 \%)$ of the patients. There was no impacted stone in 98 $(89.1 \%)$ and impacted in $21(19.1 \%)$ of the patients. The common bile duct caliber was normal in $109(99.1 \%)$ of the patients and dilated in $1(0.9 \%)$.

Operative time was less than 30 minutes in 53 (48.2\%), 3060 minutes in 46 (41.8\%), 61-90 minutes 6 (5.5\%), 91-120 minutes $3(2.7 \%)$ and more than 120 minutes in $2(1.8 \%)$ of the patients (Fig. 3). In the two cases who exceeded 120 minutes the cause was obscured anatomy. Conversion to open cholecystectomy was done for $1(0.9 \%)$ patient indicated by obscured anatomy.

There were no reported complications in $97(88.2 \%)$ of the patients, the complications were reported in $13(11.8 \%)$ were: bleeding in $8(7.3 \%)$, bile leak $3(2.7 \%)$, port site infection 1 $(0.9 \%)$ and respiratory complications $1(0.9 \%)$. The duration of hospital stay was less than 1 day in $66(60 \%)$ of the patients. Operator experience in laparoscopy was shown in (Fig. 4) as: expert 83 (75.5\%), working 20 (18.2\%), learning $5(4.5 \%)$ and starting $2(1.8 \%)$.

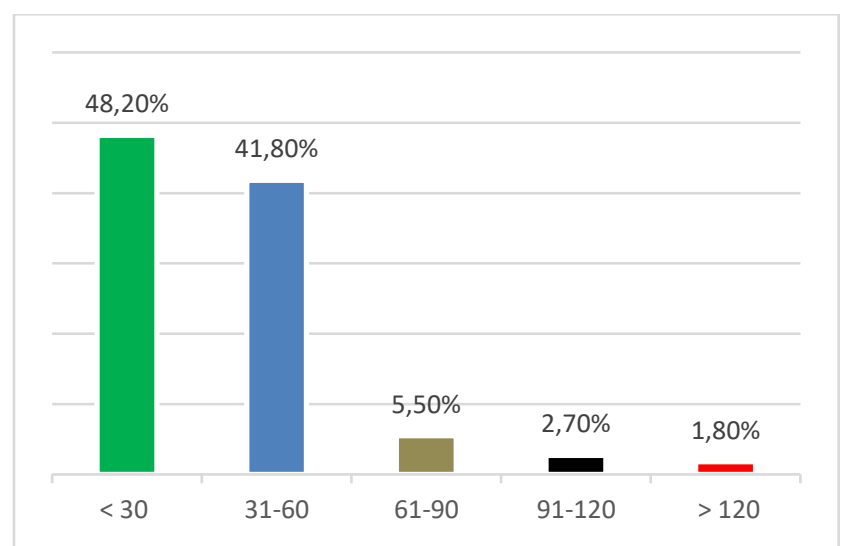

Fig. 3. Operative Time in Minutes.

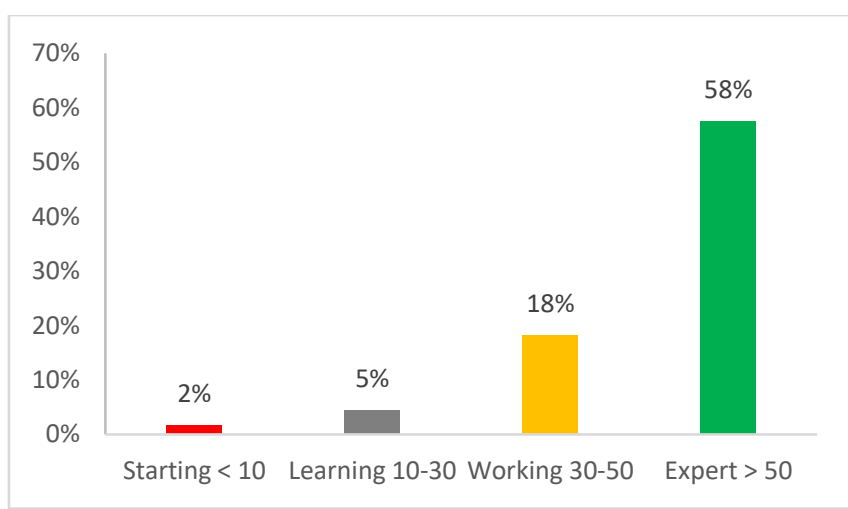

Fig IV: Operator Experience in LC

Significant association was found between GBWT, and other factors shown in Table III ( $\mathrm{P}$ value $<0.05)$.

On the other hand, operative time was also found to be significantly correlated to GBWT and the experience of the operator ( $\mathrm{P}$ value < 0.05$)$ (Tables IV and V).

TABLE III: CORRELATION BETWEEN GB WALL THICKNESS AND OTHER

\begin{tabular}{|c|c|c|c|c|c|}
\hline \multicolumn{6}{|c|}{ VARIABLES } \\
\hline & $\begin{array}{l}\text { Normal } \\
<3 \mathrm{~mm}\end{array}$ & $\begin{array}{c}\text { Mild } \\
4-5 \mathrm{~mm}\end{array}$ & $\begin{array}{c}\text { Mod } \\
\text { 6-7 mm }\end{array}$ & $\begin{array}{c}\text { Sever } \\
>7\end{array}$ & $\mathrm{P}$ \\
\hline \multicolumn{6}{|c|}{ Postoperative complications } \\
\hline Non & 64 & 28 & 5 & 0 & 0.001 \\
\hline Bleeding & 4 & 4 & 0 & 0 & \\
\hline Bile leak & 1 & 1 & 0 & 1 & \\
\hline Port site infection & 0 & 1 & 0 & 0 & \\
\hline Respiratory & 0 & 0 & 0 & 1 & \\
\hline \multicolumn{6}{|c|}{ Conversion } \\
\hline Yes & 0 & 0 & 0 & 1 & 0.018 \\
\hline No & 69 & 34 & 5 & 1 & \\
\hline \multicolumn{6}{|c|}{ Number of attacks } \\
\hline Single & 13 & 8 & 1 & 0 & \\
\hline $2-5$ attacks & 11 & 11 & 1 & 1 & 0.055 \\
\hline$>5$ attacks & 4 & 3 & 0 & 1 & \\
\hline Total & 28 & 22 & 2 & 2 & \\
\hline \multicolumn{6}{|c|}{ Hospital stay } \\
\hline$<1$ day & 43 & 22 & 1 & 0 & \\
\hline 1 - 2 days & 24 & 12 & 3 & 0 & 0.002 \\
\hline$>2$ days & 2 & 0 & 1 & 2 & \\
\hline Total & 69 & 34 & 5 & 2 & \\
\hline \multicolumn{6}{|c|}{ Duration of symptoms } \\
\hline$<1$ year & 27 & 11 & 2 & 0 & \\
\hline $1-3$ years & 28 & 12 & 0 & 1 & 0.01 \\
\hline $4-5$ years & 9 & 9 & 2 & 0 & \\
\hline$>5$ years & 5 & 2 & 1 & 1 & \\
\hline Total & 69 & 34 & 5 & 2 & \\
\hline
\end{tabular}


TABLE IV: CORRELATION BETWEEN OPERATOR LAPAROSCOPIC EXPERIENCE AND OPERATIVE TIME

\begin{tabular}{|c|c|c|c|c|c|c|c|c|}
\hline \multirow{3}{*}{ Operative time } & \multicolumn{7}{|c|}{ Operator Laparoscopic Experience } & \\
\hline & \multicolumn{2}{|c|}{ Starting $(<10)$} & \multicolumn{2}{|c|}{ Learning (10-30) } & \multicolumn{2}{|c|}{ Working (30-50) } & \multicolumn{2}{|c|}{$\overline{\text { Expert }}(>$ 50) } \\
\hline & $\mathrm{N}$ & $\%$ & $\mathrm{~N}$ & $\%$ & $\mathrm{~N}$ & $\%$ & $\mathrm{~N}$ & $\%$ \\
\hline$<30 \mathrm{~min}$ & 0 & 0.0 & 1 & 20.0 & 10 & 50.0 & 42 & 50.6 \\
\hline $31-60 \mathrm{~min}$ & 1 & 50.0 & 3 & 60.0 & 7 & 35.0 & 35 & 42.2 \\
\hline $61-90 \mathrm{~min}$ & 1 & 50.0 & 0 & 0.0 & 0 & 0.0 & 5 & 6.0 \\
\hline $91-120 \mathrm{~min}$ & 0 & 0.0 & 1 & 20.0 & 2 & 10.0 & 0 & 0.0 \\
\hline$>120 \mathrm{~min}$ & 0 & 0.0 & 0 & 0.0 & 1 & 5.0 & 1 & 1.2 \\
\hline Total & 2 & 100.0 & 5 & 100.0 & 20 & 100.0 & 83 & 100.0 \\
\hline
\end{tabular}

TABLE V: CORRELATION BETWEEN GALL BLADDER WALL THICKNESS AND OPERATIVE TIME

\begin{tabular}{ccccccccc}
\hline \multirow{2}{*}{ Operative time } & \multicolumn{9}{c}{ GB wall thickness in (mm) } \\
\cline { 2 - 8 } & \multicolumn{2}{c}{ Normal (1-3) } & \multicolumn{2}{c}{ Mild (4-5) } & \multicolumn{1}{c}{ Moderate (6-7) } & \multicolumn{2}{c}{ Severe (> 7) } \\
\cline { 2 - 8 }$y$ & $\mathrm{~N}$ & $\%$ & $\mathrm{~N}$ & $\%$ & $\mathrm{~N}$ & $\%$ & $\mathrm{~N}$ & $\%$ \\
\hline$<30 \mathrm{~min}$ & 37 & 53.6 & 15 & 44.1 & 1 & 20.0 & 0 & 0.0 \\
$31-60 \mathrm{~min}$ & 29 & 42.0 & 14 & 41.2 & 3 & 60.0 & 0 & 0.0 \\
$61-90 \mathrm{~min}$ & 2 & 2.9 & 2 & 5.9 & 1 & 20.0 & 1 & 50.0 \\
$91-120 \mathrm{~min}$ & 1 & 1.4 & 2 & 5.9 & 0 & 0.0 & 0 & 0.0 \\
$>120 \mathrm{~min}$ & 0 & 0.0 & 1 & 2.9 & 0 & 0.0 & 1 & 50.0 \\
Total & $\mathbf{6 9}$ & $\mathbf{1 0 0 . 0}$ & $\mathbf{3 4}$ & $\mathbf{1 0 0 . 0}$ & $\mathbf{5}$ & $\mathbf{1 0 0 . 0}$ & $\mathbf{2}$ & $\mathbf{1 0 0 . 0}$ \\
\hline
\end{tabular}

\section{DISCUSSION}

The aim of the study was to develop an easy and practical method of assessing the risk factors of intraoperative difficulties and conversion from laparoscopic cholecystectomy to open technique.

In this study 110 cases of laparoscopic cholecystectomy were studied in which GBWT was measured by one sonographer, using a 3D ultrasound device, studied for prediction of operative difficulties in form of operative time, dissection of gall bladder from liver bed and dissection of Calot's triangle, conversion to open, post-operative complications and post-operative hospital stay. Other demographic and socioeconomic factors, past medical and surgical history, associated diseases, and operative experience in laparoscopy were also looked at.

Male to female ratio was $0.2: 1$, Majority of them were middle age, similar to most previous studies. Nidoni et al, in their study, also addressed statistically significant relation between rate of conversion to open and number of acute attacks [6]. As the case in our study, the number of acute attacks found to be significantly related to the increase in GB wall thickness.

Majority of patients had multiple stones which were not impacted, had normal gallbladder caliber and normal wall thickness; in contrast to Kulkarni and Kumar et al who stated that multiple stones increased surgeon's difficulty and impacted stone in gallbladder neck increased the conversion rate [7].

In this study we have classified the cases according to GBWT in millimeters into 4 categories, more or less similar to the grading system of Roman SR et al [5]. We found that increasing GBWT is significantly related to complications and increase hospital stay. This was also reported Raman et al [5] and Nidoni et al [6] who precisely identify thickened gall bladder wall it by being more than $3 \mathrm{~mm}$. Chand et al from Nigeria also recommended the use of preoperative US as a screening procedure [8].

Most of the patients were found to have normal wall thickness, with increased proportion of the mild wall thickness compared to the moderate and severe grades; this might be related to the decreased maximum duration of symptoms in the majority of the patients; significant proportion of patients had 2 to 5 acute attacks, less proportion had single attacks and only 8 patients had more than 5 attacks. Severity grades of acute cholecystitis as defined by the 2013 Tokyo Guidelines, are associated with an increased rate of conversion to open surgery, and difficult cholecystectomy, as stated by Asai et al most of them had normal TWBCs count [9].

In our study, the gall-bladder wall thickness $\geq 7 \mathrm{~mm}$ among our patients significantly $(\mathrm{p}<0.05)$ increased the risk of intraoperative difficulties and conversion. In two papers concerning elective laparoscopic cholecystectomies the threshold value was $4 \mathrm{~mm}$ [10], [11]. In contrast to other papers, we included only patients with chronic cholecystitis as intramural effusion in the course of acute calcular cholecystitis, which increases the GB wall thickness, would lead to wrong conclusions [12], [13].

Three of our patients had an abnormal liver function tests with common bile duct stones, 2 of them were sent for ERCP and came back for LC. For the third one we did laparoscopic common bile duct exploration and LC.

Most of our patients had less than one-hour operative time and only two patients exceed two hours due to obscured anatomy and 1 of them was converted to open surgery, this might be related to the fact that; most of the surgeries were done by expert surgeons and their availability when needed. We found significant relation between wall thickness and increase operative time this was also concluded by Shah AA, et al, conversion to an open procedure should not be viewed as a complication but seen as a well-educated decision made by an experienced surgeon to safely care for the patient [14].

Most of our patients had minimal post-operative complications and short hospital stay decreasing expenditure for health care provider. Ibnouf et al has concluded the successfulness of day case laparoscopic cholecystectomy in Sudan back in 2006 [15], which was also found to safe and feasible by Al-Qathani et al in their study in Saudi Arabia [16]. Fry et al from the USA in their Composite of Outcomes in Medicare showed that hospitalization exceeding 3 days (96 hours) incurs an added cost [17]. Harboe K. M. et al in the revision of the Danish National Guidelines for the Treatment of Gall Stones concluded that post-operative length of stay below 2 days $(72 \mathrm{~h})$ with no hospital readmission is an indicator of an uncomplicated cholecystectomy [18]. 
Majority of our patients has no associated conditions, from those who has, diabetes mellitus was found to have significant association with increasing wall thickness; that might be related to that poor glycemic control and presence of diabetic microangiopathy and autonomic neuropathy, as well as frequent bactibilia, are important conditions that predispose diabetics to advanced forms of acute attacks and so increasing wall thickness. This similar to what was found by Boerma D. et al [19].

In our study, neither the number of acute attacks, nor the conversion found to be significantly associated with increasing GBWT this is contrast to what Nidoni et al [6] found in their study where they reported statistically significant association between the rate of conversion to open and number of acute attacks. Majority of our patients who had multiple stones which were not impacted, had a normal GBWT; in contrast to Kulkarni and Kumar who stated that; multiple stones increased surgeon's difficulty and impacted stone in gallbladder neck increased the conversion rate [20].

Rate of conversion to open surgery in our study was within the lowest percentage, which is expected within this limited time frame of the study. Even comparing to a case series from Atbara, Northern Sudan, where W. E. Abdelrahim et al who got $5 \%$ conversion to open surgery concluding that subtotal cholecystectomy is safe and can reduce the rate of conversion to open surgery in difficult laparoscopic cholecystectomy [21].

Gall bladder wall thickness on pre-operative ultrasound remains at the top of the list among factors for conversion to open cholecystectomy explored in meta-analysis by Yang et al in 2014 [22] and Josephine Rothman et al in 2016 [23]. A recent prospective cohort study in 2020 identified GBWT of more than $4 \mathrm{~mm}$ as the top significant preoperative predictor of difficult LC [24].

\section{CONCLUSION}

Pre-operative sonographic measurement of gall bladder wall thickness can be used effectively as a predictor of difficult laparoscopic cholecystectomy. Increasing GBWT is associated with difficult laparoscopic cholecystectomy in terms of conversion to open, operative time, hospital stay and post-operative complications.

Recommendation: Severe wall thickness better to be operated by an expert surgeon.

\section{ACKNOWLEDGMENT}

Sami E. E. Salah thank Dr. Khalid Eltayeb, MBBS MD Radiologist, who did the sonographic measurements, Operating Room staff in Gadarif and above all the patients who participated in the study.

\section{REFERENCES}

[1] Norman Williams, P. Ronan O'Connelland Andrew W. McCaskie. The gallbladder and bile ducts. In Baily \&Love's Short Practice of Surgery 27th Edition. CRC Press 2018 Taylor \& Francis Group Ch 67: pp: 1189-1211.
[2] Reynolds W Jr. The first laparoscopic cholecystectomy. JSLS. 2001 Jan-Mar; 5(1):89-94. PMID: 11304004; PMCID: PMC3015420.

[3] Ibn Ouf Mohamed A.M, Salama Ali A, Fedail Sulaiman S. Laparoscopic cholecystectomy: A local experience in Sudan. The Saudi Journal of Gastroenterology. 2001; 7 (1): 22-25

[4] STEPHEN J. HANDLER. Ultrasound of Gall Bladder Wall Thickening and its relation to Cholecystitis. AJR April 1979; 132: 581585 .

[5] Raman SR, Moradi D, Samaan BM, Chaudhry US, Nagpal K, Cosgrove JM, Farkas DT. The degree of gallbladder wall thickness and its impact on outcomes after laparoscopic cholecystectomy. Surg Endosc. 2012 Nov; 26(11):3174-9. doi: 10.1007/s00464-012-2310-8 Epub 2012 Apr 27. PMID: 22538700.

[6] Nidoni R, et al. Predicting Difficult Laparoscopic Cholecystectomy Based on Clinicoradiological Assessment. J Clin Diagn Res. 2015; 9(12): PC09-PC12.

[7] Kulkarni SV, Kumar SS. Preoperative predictors of a difficult laparoscopic cholecystectomy. Int Surg J 2018; 5: 608-13.

[8] Chand P, Singh R, Singh B, Singla RL, Yadav M. Preoperative Ultrasonography as a Predictor of Difficult Laparoscopic Cholecystectomy that Requires Conversion to Open Procedure. Niger J Surg. 2015; 21(2): 102-105.

[9] Asai K, Watanabe M, Kusachi S, Matsukiyo H, Saito T, Kodama H, et al. Risk factors for conversion of laparoscopic cholecystectomy to open surgery associated with the severity characteristics according to the Tokyo guidelines. Surg Today. 2014 Dec; 44 (12): 2300-4.

[10] Corr P, Tate JJ, Lau WY, Dawson JW, Li AK. Preoperative ultrasound to predict technical difficulties and complications of laparoscopic cholecystectomy. Am J Surg. 1994 Jul; 168 (1):54-6.

[11] Goonawardena J, Gunnarsson R, de Costa A. Predicting conversion from laparoscopic to open cholecystectomy presented as a probability nomogram based on preoperative patient risk factors. Am J Surg. 2015 Sep; 210 (3):492-500.

[12] Hirota M, et al. Diagnostic criteria and severity assessment of acute cholecystitis: Tokyo Guidelines. J Hepatobiliary Pancreat Surg. 2007; $14(1): 78-82$

[13] Yokoe M, et al. TG13 diagnostic criteria and severity grading of acute cholecystitis (with videos). J Hepato- biliary Pancreat Sci. [Practice Guideline]. 2013 Jan; 20 (1):35-46

[14] Shah AA, Bhatti UF, Petrosyan M, Washington G, Nizam W, Williams $\mathrm{M}$, et al. The heavy price of conversion from laparoscopic to open procedures for emergent cholecystectomies. Am J Surg. 2019; 217 (4):732-8

[15] MAM Ibnouf, Mohamed Mahmoud, Yosif A Abdulgadir, Ali A Salama, El Tayb El Amri, Day case laparoscopic cholecystectomy in Sudan, Sudan JMS, Vol 1, No.1, Sept 2006.

[16] Al-Qahtani HH, Alam MK, Asalamah S, Akeely M, Ibrar M. Day-case laparoscopic cholecystectomy. Saudi Med J. 2015; 36(1):46-51. doi:10.15537/smj.2015.1.9738

[17] Fry DE, Pine M, Locke D, Pine G. Composite measurement of outcomes in medicare inpatient laparoscopic cholecystectomy. J Am Coll Surg. [Evaluation Studies Research Support, Non-U.S. Gov't]. $2015 \mathrm{Jul} ; 221$ (1):102-9.

[18] Kirstine M. Harboe, Linda Bardram, Nationwide quality improvement of cholecystectomy: results from a national database, International Journal for Quality in Health Care, Volume 23, Issue 5, October 2011 , Pages 565-573.

[19] Paajanen H, et al. Laparoscopic versus open cholecystectomy in diabetic patients and postoperative outcome. Surg Endosc. [Evaluation Studies]. 2011 Mar; 25 (3):764-70.

[20] Kulkarni SV, Kumar SS. Preoperative predictors of a difficult laparoscopic cholecystectomy. Int Surg J 2018; 5: 608-13.

[21] Abdelrahim WE, et al. Subtotal laparoscopic cholecystectomy influences the rate of conversion in patients with difficult laparoscopic cholecystectomy: Case series. Ann Med Surg (Lond). 2017;19: 19-22.

[22] Yang TF, Guo L, Wang Q. Evaluation of Preoperative Risk Factor for Converting Laparoscopic to Open Cholecystectomy: A Meta-Analysis. Hepatogastroenterology. 2014 Jun; 61 (132):958-65. PMID: 26158149

[23] Philip Rothman J, Burcharth J, Pommergaard HC, Viereck S, Rosenberg J. Preoperative Risk Factors for Conversion of Laparoscopic Cholecystectomy to Open Surgery - A Systematic Review and Meta-Analysis of Observational Studies. Dig Surg. 2016;33(5):414-23.

[24] Stanisic V, Milicevic M, Kocev N, Stanisic B. A prospective cohort study for prediction of difficult laparoscopic cholecystectomy. Ann Med Surg (J. U. Duncombe, "Infrared navigation-Part I: An assessment of feasibility," IEEE Trans. Electron Devices, vol. ED-11, pp. 34-39, Jan. 1959 


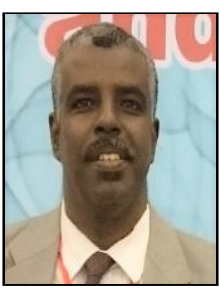

Sami E. E. Salah was born in Gadarif $24^{\text {th }}$ August 1969. MBBS University of Gezira, Wad-Madani, Sudan 1993

MD Clinical Surgery, University of Khartoum, Khartoum, Sudan 2000. Diploma in Laparoscopic Surgery: Louis Pasteur University Strasbourg, France 2008. Fellowship of the American College of Surgery 2018.

$\mathrm{He}$ is an Associate Professor of Surgery, currently Dean Faculty of Medicine, Gadarif University, formerly Assistant Professor and Head Department of Surgery. With 25 published articles in National and International Journals. The most recent are:

[1] Sami E. S., Sami G. E. E M., Marwa O. Z., Saeed M O, Majdi A. O. B. Non-Operative Management of Splenic Injuries (NOMSI) in a Limited Resources Setup. Adv Res Gastroentero Hepatol, 2020; 16 (1): 555926. DOI: 10.19080/ARGH.2020.16.555926 03.

[2] Sami E. E. Salah; Khalid I. Elhaj, Yasir O. M. Awadelseed, Sami G. E. E. Mohammed. Crossed Testicular Ectopia: A Case Report and Review of the Literature. Annals of Pediatric Surgery: 2016; 12: 170-172.

[3] Sami E. E. Salah, Sami Galal-eldin Elazhary, Rehab Elmushly. Presentation and Outcome of Management of Parotid Tumors: A Local Experience from Two Sudanese States. Gezira Journal of Health Sciences. June 2015; 11: (1): 39-51.

His current interest research is in Laparoscopic Surgery and Medical Education.
Dr. Salah is member of Sudanese Association of Surgeon, Sudanese Society of Gastroenterology, International Society of Surgery, European Association of Endoscopic Surgery, International Association of Surgeons, Gastroenterologists \& Oncologists, Arab Board of Health Specialization, General Surgery Scientific Council and Instructor/Course Director of ATLSR.

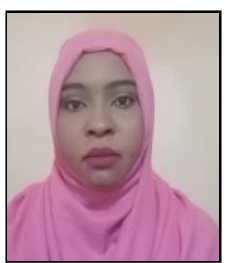

Hawa Y. A. Osman was born in Kadogli, Sudan 12th October 1988.

MBBS University of Khartoum, Khartoum, Sudan 2012, MRCS ed.

She is working as general surgeon Ibrahim Malik Teaching hospital, Khartoum, Sudan. With a single published article in the international journal of surgery case report:

[1] S. Eldirdiri, I. H. Musa, H. Y. Adam, A. G. Suliman, M. M. A. Elmanan, S. Eldirdiri, Yasir O. M. Awadelseed, Majdi O. A. Bakhiet. Transverse colonic volvulus after resection of sigmoid volvulus: Presentation of a case report. International Journal of Surgery Case Reports. 2019;60:257-260. https://doi.org/10.1016/j.ijscr.2019.06.008.

Dr. Yahia is member of Sudanese Association of Surgeon, and ATLS $\AA$ provider. 